\title{
ПРОСОПОГРАФИЧЕСКАЯ РЕКОНСТРУКЦИЯ СОКРАЩЕННЫХ И ФРАГМЕНТИРОВАННЫХ ИМЕН ИСТОРИЧЕСКИХ ЛИЦ (НА ПРИМЕРЕ ОЛЬВИИ)*
}

\author{
Николай Николаев \\ Независимый исследователь (г. Николаев, Украина) \\ e-mail: olbiopol@gmail.com \\ ORCID: https://orcid.org/0000-0003-3994-1150
}

\begin{abstract}
У процесі відновлення літочислення Ольвії IV-I cm. до н.е. отримано просопографічні відомості про вищу еліту. Це дозволяє обгрунтувати просопографічну реконструкцію відновлення деяких фрагментів і скорочень у лапідарній, керамічній, магічній і нумізматичній епіграфіці іменами реальних історичних осіб. Виконана автором десять років тому за двома літерами імені просопографічна реконструкція фрагмента посвяти епоніма Ольвії 195 р. до н.е. Пантакла Клеомбротова піддалася жорсткій і потворній критиці В.П. Яйленка з традиційних (ономастичних) позицій. У статті на 100\% подолана критика та доведена істинність виконаної раніше реконструкції шляхом возз'єднання фрагмента посвяти з відомим раніше написом.
\end{abstract}

Ключові слова: Ольвія, епіграфіка, реконструкція, ономастика, просопографія

Древние надписи ученые обнаруживают, как правило, в поврежденном виде. Соответственно, обоснованная реконструкция, в частности, фрагментов имен исторических лиц ${ }^{1}$ всегда остается актуальной. При реконструкции фрагментированных имен в эпиграфике традиционно используется ономастический принцип: фрагмент дополняется подходящими именами с учетом примерного количества недостающих букв. Например, в сборнике «Надписи Ольвии. 1968» (далее - IOlb) фрагмент [...] tov



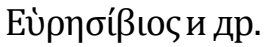

Ономастические реконструкции широко применялись В.В. Латышевым в его труде «Latyshev B. Inscriptiones antique orae septentrionalis Ponti Euxini Graecae et Latinae. Petropolis. 1916» (далее - IPE I²) и другими исследователями, (например, см. «Supplementum epigraphicum Graecum. Brill» (далее - SEG)); при этом восстановленные имена зачастую никогда не встречались ни в Ольвии, ни в Северном Причерноморье.

Несколько усовершенствовал традиционный ономастический принцип П.О. Карышковский${ }^{2}$ при расшифровке монетных легенд: сокращения, в первую очередь, восстанавливались именами, известными в Ольвии, во вторую - именами, известными в Милете и, наконец, общегреческими именами. Ономастическая реконструкция имен, предполагая многообразие возможных теоретических вариантов,

\footnotetext{
* Автор выражает искреннюю благодарность Аскольду Игоревичу Иванчику, гипотеза которого о том, что материалом посвящения SEG 58: 766 является не гранит, а серый мрамор, создала начальный импульс для этого исследования.

1 Виноградов Ю.Г. О методике обработки греческих эпиграфических памятников (по ольвийским материалам) // Методика изучения древнейших источников по истории народов СССР: сб. ст. / [отв. ред. В.Т. Пашуто]. Москва: Наука, 1978. С. 46-75.

2 Карышковский П.О. Монетное дело и денежное обращение Ольвии. Одесса, 2003. С. 131-132.
} 
остается в сущности условной, поскольку не связана с конкретной исторической личностью. Соответственно, целью статьи является обоснование и защита принципиально иной, просопографической реконструкции фрагментированных (сокращенных) имен исторических лиц, также, преодоление критических замечаний оппонента. Цель статьи достигается путем подтверждения выполненной 10 лет назад просопографической реконструкции фрагмента посвящения SEG 58:766 при объединении его с ранее известной надписью IOlb 125.

Выполненное автором некоторое время назад восстановление летоисчисления Ольвии IV-I вв. до н.э. (синхронизация эпонимного каталога IPE I2 201) открыло перспективу замены традиционной ономастической реконструкции принципиально иным, однако, совершенно очевидным подходом к реконструкции фрагментов и сокращений имен в памятниках лапидарной, керамической, магической эпиграфики и нумизматики именами реальных исторических лиц - просопографической реконструкции. Как известно, просопография, в силу своей относительной «молодости», традиционно считается вторичной по отношению к ономастике, лингвистике и палеографии. Парадокс состоит в том, что при достижении соответствующего уровня изучения конкретной городской общины, например, Ольвии, просопография становится доминирующей в исследовании памятников, содержащих имена исторических лии, в том числе, в виде фрагментов или сокращений․

В городской общине античного полиса весьма ограниченное количество лиц упоминалось в лапидарных или иных надписях и монетных легендах. Эти реальные исторические личности - выходцы из высшей элиты 4 . В частности, восстановление эпонимного летоисчисления позднеклассической-эллинистической Ольвии сопровождалось получением репрезентативных просопографических сведений о выходцах из семи элитных родов. Деятельность их отмечена в 92\% лапидарных надписей a, также, синхронных керамических, магических и нумизматических памятниках Выявлена и главная проблема просопографии - традиция передачи родовых имен от деда ко внуку.

Просопографический подход, предполагающий обязательное наличие репрезентативной информации о высшей полисной элите, в настоящее время не может быть реализован, например, для такого города как Никоний, но уже, кроме Ольвии, в Северном Причерноморье используется для Херонеса Таврического 5 . В ольвийской нумизматике с помощью просопографии идентифицированы именами реальных исторических лиц десятки сокращений и монограмм. Например, с использованием известного факта хронологической близости исполнения эпонимной и магистратской должностей, выявлен непрерывный ряд сокращений, тождественных эпонимам

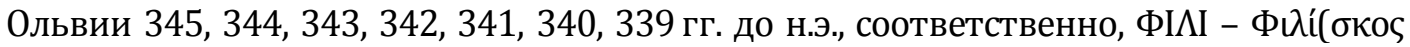

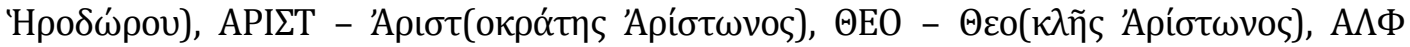

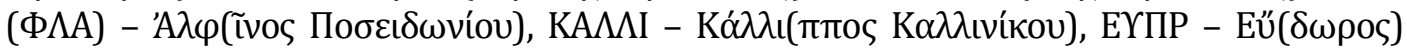

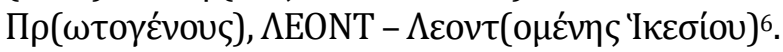

\footnotetext{
3 Николаев Н.И. Развитие просопографической модели общины небольшого античного города (на примере Ольвии) //Древние цивилизации: социум и человек. ЯрГУ. 2018. С. 99.

4 Николаев Н.И. Просопография Ольвии Понтийской V в. до н.э. -I в. н.э. Киев, 2014.

5 Туровский Е.Я. Личные имена на херсонесских монетах и керамические клейма: опыт сравнения // Античный мир и археология. 2015. № 17. С. 342-351.

6 Ніколаєв М.І. Монетні магістрати Ольвї 380-330 рр. до н.е. // Актуальні проблеми нумізматики у системі спеціальних галузей історичної науки: тези доповідей V міжнародної науково-практичної конференції. Меджибіж - Переяслав-Хмельницький - Кропивницький - Київ, 2018. С. 10-12.
} 
Спецификой применения просопографии в магической и керамической эпиграфике является идентификация в ряде случаев исторических лиц, представленных только именами (без патронимов). Так, многострочный магический опистограф из Ольвии середины IV в. до н.э. (не опубликован), восстанавливается полными именами лиц, бывших эпонимами в 357, 356, 355, 347, 344 гг. до н.э., соответственно,

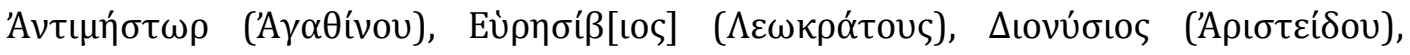

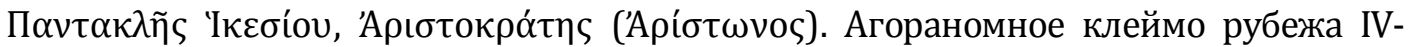
III вв. до н.э. АГОРA \[...]KE $\Sigma$ ANTI \MENAN может быть реконструировано имена-

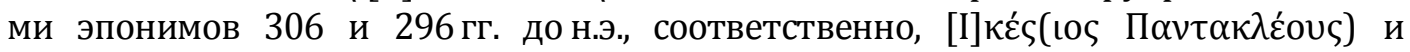

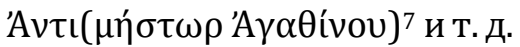

Высшая ступень использования просопографии - восстановление существенно фрагментированных имен в лапидарных надписях ${ }^{8}$. «Классическим» примером, получившим высокую оценку такого специалиста как A. Avram9 , является идентификация реальными историческими лицами - эпонимами 355 и 327 гг. до н.э. - имен из посвящения IOlb 168, вероятно, жрецов Леократа по остаткам патронимов [...] $\delta$ оu и [...]орос (рис. 1).

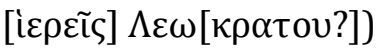

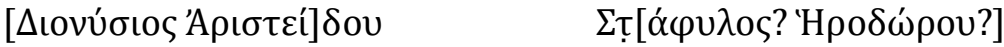

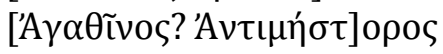



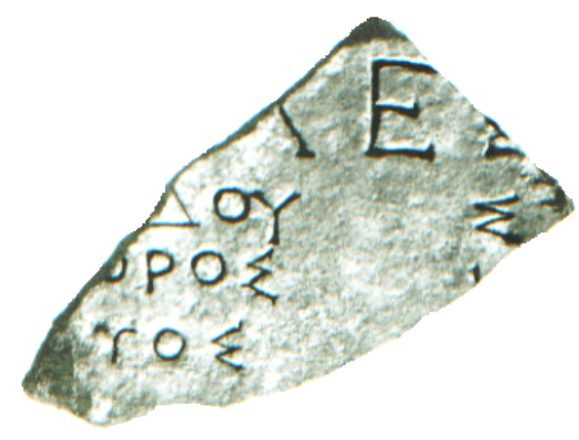

Рис. 1. Посвящение IOlb 168.

Очевидны принципиальные отличия традиционной ономастической реконструкции от реконструкции просопографической. Тем не менее, восстановленное в 2008 г. путем просопографической реконструкции существенно фрагментированное посвящение SEG 58 : 766 Пантакла (II) Клеомбротова10 некоторое время назад

\footnotetext{
7 Ніколаєв М.І. Агораноми елліністичної Ольвії // Історія торгівлі, податків та мита: Зб. наук. праць. Дніпро. 2017. № 1 (15). С. 16.

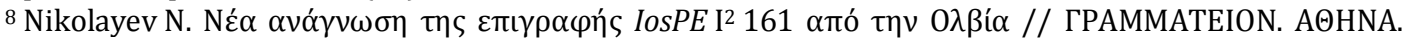
2013. № 2. $\Sigma \varepsilon \lambda$. 67-70.

${ }^{9}$ Николаев Н.И. Просопография Ольвии Понтийской V в. до н.э. - I в. н.э. Киев, 2014. С. 169-172; Avram A. N.I. Nikolaev. Prosopografiya Olvii Pontiiskoi V v. do n.e. - Iv. n.e. // Ancient West \& East. 2017. № 16. Р. 441-442. Эта реконструкция получила недавно новое подтверждение в магической надписи (не опубликовано).

10 Николаев Н.И. Политическая и культовая элита Ольвии IV-I вв. до н.э. Николаев, 2008. С. 11-15.
} 
стало объектом жесткой критики В.П. Яйленко ${ }^{11}$.

Следует, однако, начать с изложения некоторых обстоятельств обнаружения и изучения этого памятника. В начале 1990-х гг. выдающиеся исследователи Ольвии А.С. Русяева и В.В. Крапивина опубликовали группу посвятительных надписей, найденных на участке Р-1912. Среди них выделялась группа посвящений, датируемая издателями первой половиной II в. до н.э. - Леона Гераклидова, Евника Евдорова, Гикесия Филтова и неизвестного дедиканта. По мнению издателей, все постаменты были изготовлены из серого гранита. В дальнейшем посвящения участка Р-19 обрели просопографическую интерпретацию и уточненную датировку13.

В 2008 г. в научный оборот был введен фрагментированный постамент из частного собрания - случайная находка вблизи участка Р-19 (рис. 2)14. На этом основании и с учетом внешнего сходства материала с упомянутыми выше надписями первой половины II в. до н.э., издатель также определил материал посвящения как серый гранит.

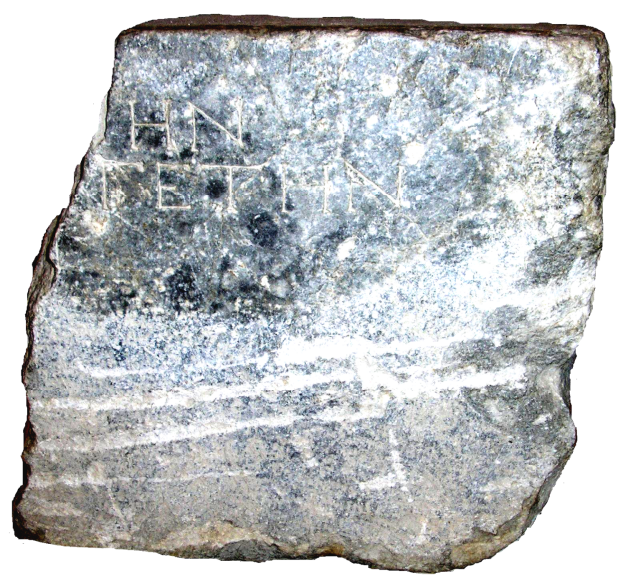

Рис. 2. Посвящение SEG 58:766.

Надпись содержала остатки двух строк и фрагмент вертикальной гасты буквы третьей строки [...]HN/ [...]ГЕTHN / [...]I. Совершенно очевидна здесь бесспорная

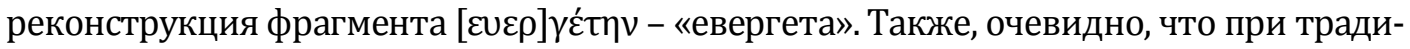
ционном ономастическом подходе фрагмент [...]ๆv восстанавливается огромным количеством имён, имеющих соответствующее окончание. Тем не менее, фрагмент был дополнен именем реальной исторической личности - Пантакла (II) Клеомбротова, эпонима 195 г. до н.э. Обоснование просопографической реконструкции выполнялось с опорой на единую хронологическую и просопографическую основу исто-

\footnotetext{
11 Яйленко В.П. История и эпиграфика Ольвии, Херсонеса, Боспора VII в. до н.э. - VII в. н.э. СанктПетербург, 2017. С. 484. Критика базируется на традиционном ономастическом принципе и оформлена в стиле, далеком от научной дискуссии: «...как он управляется с надписями, видно с самого начала книги...», «...кроме слова евергет, все здесь туфта....», «...в надписи ... могло быть любое имя на -пи».

12 Русяєва А.С., Крапівіна В.В. До історії Ольвії IV-I ст. до н.э. // Археологія. 1992. № 4. С. 17-33.

13 Николаев Н.И. Политическая и культовая элита Ольвии... С. 244-245.

14 Ibid. C. 11-15.
} 
рии Ольвии (эпонимный каталог IPE I2 201), аналогичные по материалу посвящения участка Р-19 и узкий хронологический диапазон их датировки, традиции евергетизма и стеностроительства в роду Пантаклов-Клеомбротов, репрезентативную стемму рода, принадлежащего к высшей элите Ольвии, гентильное божество рода (Геракл) и ожидаемую находку посвящения Пантакла (II) Клеомбротова, эпонима 195 г. до н.э. При этом, уже известны посвящения IPE I2 179, IPE I2 188, IPE I2 180, соответственно, Клеомброта (I) Пантаклова, эпонима 317 г. до н.э. и магистрата К $\Lambda$ (I), также, Пантакла (I) Клеомбротова, вероятного эпонима ок. 280-240 гг. до н.э., упоминаемого, очевидно, в defixio 15 и Клеомброта (II) Пантаклова, эпонима 222 г. до н.э. и магистрата K $\Lambda$ E (II). В итоге, публикуемая надпись $S E G$ 58:766, была реконструирована по аналогии с посвящением IPE I2 188 Пантакла (I) Клеомбротова как

\section{[ò $\delta \tilde{\eta} \mu о \varsigma ~ П \alpha \nu \tau \alpha \kappa \lambda(?)] \tilde{\eta} v$

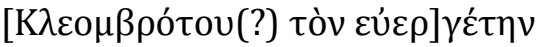

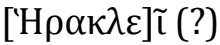

и интерпретирована, как, вероятно, посвящение Гераклу эвергета и эпонима 195 г. до н.э. Пантакла (II) Клеомбротова16.

Между тем, А.И. Иванчик, выполнив de visu посвящения $S E G$ 58:766 в рамках проекта IOSPE III, сообщил издателю, что у него не возникло сомнений в подлинности памятника; это оказалось весьма актуальным в свете новых материалов исследователя ${ }^{17}$. Кроме того, А.И. Иванчик предположил, что материал посвящения SEG 58:766 - скорее всего, не гранит, а серый мрамор. После ознакомления с соответствующей технологией, издателем были выполнены сравнительные замеры твердости материала посвящения $S E G$ 58:766 и эталонных образцов из мрамора и гранита18. Гипотеза А.И. Иванчика подтвердилась - материал постамента посвящения SEG 58:766 серый плотный мрамор. Сведения, устраняющие неточное определение А.С. Русяевой и В.В. Крапивиной материала группы посвящений Леона Гераклидова, Евника Евдорова, Гикесия Филтова и неизвестного дедиканта с участка Р-19, обнаружены позднее - серый мрамор ${ }^{19}$.

\footnotetext{
15 Belousov A., Dana M., Nikolaev N. Deux nouvelles defixionum tabellae du territoire d'Olbia du Pont // Zeitschrift für Papyrologie und Epigraphik. 2016. Bd. 197. S. 167-177.

16 Николаев Н.И. Политическая и культовая элита Ольвии... С. 11-15; Николаев Н.И. Просопография Ольвии Понтийской... С. 305.

17 Хранящееся в Одессе посвящение IPE I2 188 Пантакла (I) Клеомбротова (послужившее прототипом к реконструкции) - подделка; подлинник находится в херсонском музее (см.: Иванчик А.И. О некоторых поддельных надписях Ольвии и Тиры // Olbio. In memoriam V.V. Krapivina (Apхеологія і давня історія України. Вип. 1 (14)). Киев, 2015. С. 147-157. Соответственно, А. Аврам (см.: Avram A. Bulletin épigraphique. 2016. Р. 345) высказал совершенно справедливое сомнение, в том, а не является ли подделкой и надпись $S E G 58: 766$, учитывая предполагаемую идентичность текстов. А.В. Белоусов per expressum привел комментарий издателя посвящения: оно «...относится к внуку Пантакла (I) Клеомбротова, и, соответственно, датируется 200-180 гг. до н.э. Эта личность, Пантакл (II) Клеомбротов, - эпоним 195 г. до н.э.». (См.: Белоусов А.В. Греческая и римская эпиграфика Северного Причерноморья в 2015 г. // Аристей. 2016. Вып. XIV. С. 255.

18 Тведость по Роквеллу: гранитные образцы: 57,2 и 53,6; мраморные образцы: 24,4 и 25,3; посвящение: 34,8 и $30,9$.

19 Трейстер М.Ю. Материалы к корпусу постаментов бронзовых статуй Северного Причерноморья // Херсонесский сборник. 1999. Вып. 10. С. 121-158.
} 
Уточнение материала посвящения $S E G 58: 766$, кроме прочего 20 , влечет за собой очевидную необходимость пересмотра лапидарного архива Ольвии, с целью поиска иных фрагментов, принадлежащих этому памятнику. Практическая реализация этого вопроса, однако, упрощается наличием найденного в 1947 г. на агоре фрагмента IOlb 125 верхней части плиты из серого плотного мрамора, интерпретируемого издателями как посвящение Пантаклов-Клеомбротов (рис. 3). Характер обработки поверхностей обоих фрагментов полностью совпадает: лицевые поверхности сглажены, а на горизонтальных поверхностях видны следы инструмента. Это обстоятельство определяет перспективу выполнения соответствующего исследования по возможности воссоединения фрагментов SEG 58:766 и IOIb 125.

Во фрагменте IOlb 125 сохранилась частично первая строка, восстанавливаемая

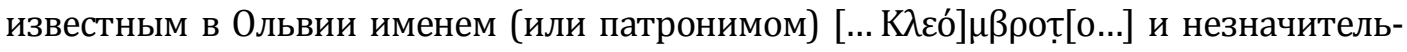
ные следы букв второй. Издатель отнес надпись к посвятительным и датировал ее не ранее конца III-II вв. до н.э. Объединённые горизонтальной чертой вверху, крупные литеры бета и ро фрагмента IOlb 125, выходят за верхний габарит строки, имея высоту 27 мм (по Е.И. Леви ${ }^{21}$ - 30 мм) и отстоят от верхнего края на 55 мм. Они соседствуют с малыми литерами омикрон и мю, высотой, соответственно, 15 и 17 мм (по Е.И. Леви $22-16$ мм). В целом шрифт (в том числе, геометрические пропорции и взаимное расположение больших и малых литер) подобен посвящению IPE I2 188 Пантакла (I) Клеомбротова.

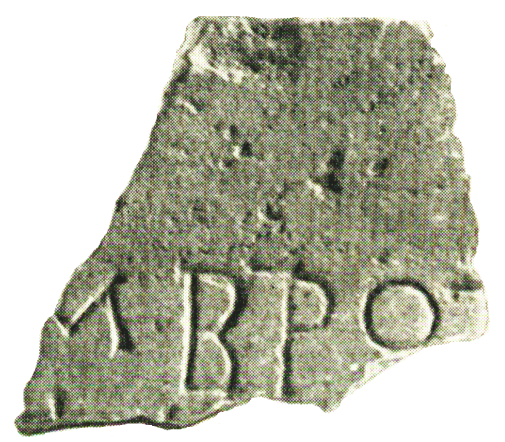

Рис. 3. Посвящение IOlb 125.

Вероятная идентичность текстов посвящений IPE I2 188 и SEG 58:766, высказанная в 2008 г., сопровождалась их композиционным отличием; в посвящении $I P E$ I2 $^{2} 188$ имя и патроним выполнены в одной строке, а в посвящении SEG 58:766 имя в первой строке, патроним - во второй 23 . Таким образом, с учетом композици-

\footnotetext{
20 Потребуется ревизия выполненной ранее просопографической реконструкции посвящения IPE I2 163. Вероятно, появляется новый аргумент в датировке первой четвертью II в. до н.э. посвящений Афродите Евплойе, Зевсу Атабирию и богине Родос из Ольвии и Неаполя Скифского, установленных Посидеем Посидеевым и изготовленных из серого мрамора. Перспективно по ряду причин изучение фрагмента посвящения IPE I2 194, изготовленного из «marmoris subcaerulei», субъективно близкого к серому мрамору. Однако, серый мрамор посвящения IPE I2 188 Пантакла (I) Клеомбротова показывает, что какие-либо преждевременные выводы здесь неуместны.

21 Леви Е.И. Ольвийская агора // Ольвия и Нижнее Побужье в античную эпоху / Под ред. В.Ф. Гайдукевича. 1956. С. 110.

22 Ibidem.

23 Николаев Н.И. Политическая и культовая элита Ольвии... С. 11-15.
} 
онного оформления надписи $S E G$ 58:766 (наличие свободного пространства в начале первой строки) остатки букв $\mu$ рот фрагмента IOIb 125 принадлежат левой части второй строки посвящения $S E G 58: 766$. Обращаясь к геометрическим параметрам посвящения $S E G$ 58:766 можно отметить, что высота сохранившихся литер (эта, ню, гамма, эпсилон) составляет 23-25 мм. Это указывает на их соответствие размеру шрифта фрагмента IOlb 125 , включающего в себя удлинённые литеры (бета, po) и малые литеры (омикрон, мю).

Первая строка посвящения SEG 58:766 отстоит от верхнего края плиты на 3234 мм, соответственно, нижний ее габарит - на 55-57 мм, что совпадает с расстоянием первой строки посвящения IOlb 125 до верхнего края плиты - 55 мм (данные издателя) (рис. 4).

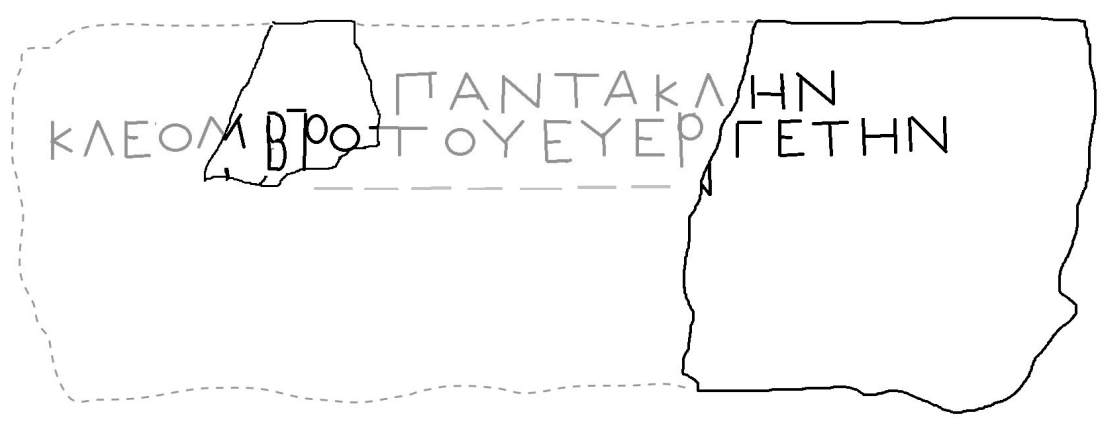

Рис. 4. Посвящение SEG 58:766+IOIb 125.

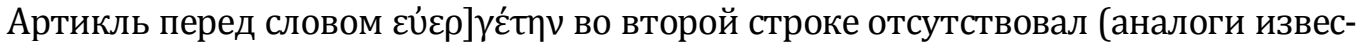
тны). Изучение остатков литеры в третьей строке воссоединенного посвящения, указывает на правую гасту ню. Таким образом, и с учетом остатков литер второй строки посвящения IOlb 125 реконструкция третьей строки посвящения SEG 58:766+IOlb 125 может быть только сугубо гипотетической. Не исключено, что третья строка начинается как о̀ $\delta \tilde{\eta} \mu о \varsigma$.

Воссоединение фрагментов (не в контакте) дает связный текст и вносит некоторые коррективы в реконструируемый ранее текст посвящения 24 , который, вероятно, был таким:

vac. $[\Pi \alpha \nu \tau \alpha \kappa \lambda] \tilde{\eta} \nu$

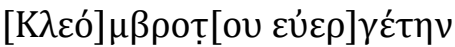

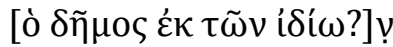

Перевод: Пантакла Клеомбротова, евергета [народ посвятил за собственные средства?].

Реконструируемая ширина постамента - ок. 72 см, при фактической высоте 32 см, что совпадает с размером посвящения Евника Евдорова25. При этом Пантакл (II) Клеомбротов исполнил эпонимию в 195 г. до н.э., а Евник Евдоров - в 193 г. до н.э. Посвящение SEG 58:766+IOIb 125 было разбито в древности. Фрагмент SEG 58:766 перетащили для укрепления участка P-19, фрагмент IOlb 125 оставался на агоре (теменосе), где и был найден.

\footnotetext{
${ }^{24}$ De visu фрагмента IOlb 125 не проводился. Третья строка показана лишь как вариант реконструкции.

25 Русяєва А.С., Крапівіна В.В. До історії Ольвії IV-I ст. до н.э. // Археологія. 1992. № 4. С. 17-33.
} 
В научный оборот введено реальное подтверждение истинности алгоритма просопографической реконструкции путем однозначного подтверждения выполненной 10 лет назад реконструкции фрагментированного посвящения SEG 58:766 эпонима 195 г. до н.э. Пантакла (II) Клеомбротова (по остаткам имени [...] $\eta$ ) путем объединения его c посвящением IOIb 125. Кроме прочего, полученный результат свидетельствует в пользу восстановленного летоисчисления позднеклассической-эллинистической Ольвии и построения основ ее просопографии. Критика В.П. Яйленко ошибочна и несостоятельна методически: ученый, кроме прочего, рассматривает с традищионных позиций результат, полученный принципиально иным путем. Следует напомнить В.П. Яйленко: наука не остановилась в 80-90 г2. прошлого века.

\section{REFERENCES}

Avram, A. (2016). Bulletin épigraphique. Paris [in French].

Avram, A. (2017). N.I. Nikolaev. Prosopografiya Olvii Pontiiskoi V v. do n.e. - I v. n.e. Ancient West \& East, 16, 441-442 [in French].

Belousov, A., Dana, M., \& Nikolaev, N. (2016). Deux nouvelles defixionum tabellae du territoire d'Olbia du Pont. Zeitschrift für Papyrologie und Epigraphik, 197, 167-177 [in French].

Belousov, A.V. (2016). Grecheskaia i rimskaia epigrafika Severnogo Prichernomoria v 2015 g. [The Greek and Latin inscriptions of Ancient North Black Sea Region in 2015]. Aristei, XIV, 246-273 [in Russian].

Ivanchik, A.I. (2015). O nekotorykh poddelnykh nadpisiakh Olvii i Tiry [Some Fake Inscriptions from Olbia and Tyras]. Arkheologiia i davnia istoriia Ukrainy, 1 (14) [Olbio. In memoriam V.V. Krapivina], 147-157 [in Russian].

Karyshkovskii, P.0. (2003). Monetnoe delo i denezhnoe obrashchenie Olvii [Coins of Monetary Circulation in Olbia]. Odessa [in Russian].

Levi, E.I. (1956). Olviiskaia agora [Agora of Olbia]. In Olviia i Nizhnee Pobuzhe v antichnuiu epokhu (pp. 35-118) [in Russian].

Nikolaev, N.I. (2008). Politicheskaia i kultovaia elita Olvii IV-I vv. do n.e. [Political and cult Olbian elite IVI cent. B.C.]. Nikolaev [in Russian].

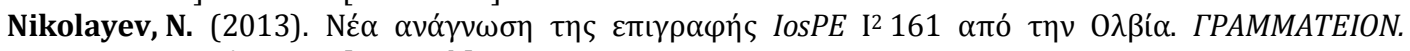
$A \Theta H N A, 2 . \Sigma \varepsilon \lambda$, 67-70 [in Greek].

Nikolaev, N.I. (2014). Prosopografiia Olvii Pontiiskoi Vv. do n.e. - Iv. n.e. [Prosopography of Olbia Pontika V cent. B.C. - cent. A. D.]. Kyiv [In Russian].

Nikolaev, M.I. (2017). Ahoranomy ellinistychnoi Olvii [Agoranoms of the Hellenistic Olbia]. Istoriya torhivli, podatkiv ta myta, 1 (15), 12-30 [in Ukrainian].

Nikolaev, N.I. (2018). Kriticheskie zametki k monografii V.P.Yailenko «Istoria i epigrafika Olvii, Khersonesa, Bospora VII v. do n.e. - VII v. n.e.». [Critical notes to the monograph by V.P. Yailenko «A History and Epigraphy of Olbia, Chersonesus and Bosporus VII Century B.C. - VII Century A.D.»]. Eminak, 22 (1), 155-159 [in Russian].

Nikolaev, N.I. (2018). Razvitie prosopograficheskoi modeli obshchiny nebolshogo antichnogo goroda (na primere Olvii) [Development of a Prosopographical Model of a Small Ancient City Community (on the Example of Olbia)]. In Drevnie tsivilizatsii: sotsium i chelovek. Yaroslavl (pp. 99-104) [in Russian].

Nikolaiev, M.I. (2018). Monetni mahistraty Olvii 380-330 rr. do n.e. [Coins magistrates of Olbia of 380330 B.C.]. In Aktualni problemy numizmatyky u systemi spetsialnykh haluzei istorychnoi nauky: tezy dopovidei v mizhnarodnoi naukovo-praktychnoi konferentsyi. Medzhybizh - Pereiaslav-Khmelnytskyi - Kropyvnytskyi - Kyiv (pp. 10-12) [in Ukrainian].

Rusiaeva, A.S. \& Krapivina, V.V. (1992). Do istorii Olvii IV-I ct. do n.e. [Concerning History of Olbia $4^{\text {th }}$ 1 st cent. BC]. Arkheolohiia, 4, 17-33 [in Ukrainian].

Treister, M.Yu. (1999). Materialy k korpusu postamentov bronzovykh statui Severnogo Prichernomoria [Materials for the catalogue of the pedestals of bronze statues of the Northern Black Sea region]. Khersonesskii sbornik, 10, 121-158 [in Russian].

Turovskii, E.Yi. (2015). Lichnye imena na khersonesskikh monetakh i keramicheskie kleima: opyt sravneniia [Personal names on Chersonesus coins and ceramic stamps: a comparison experience] Antichnyi mir i arkheologiia, 17, 342-351 [in Russian].

Vinogradov, Yi.G. (1978). O metodike obrabotki grecheskikh epigraficheskikh pamiatnikov (po olviiskim materialam) [On the method of processing Greek epigraphic monuments (according to the Olbian 
materials)]. Metodika izucheniia drevneishikh istochnikov po istorii narodov SSSR, $46-75$ [in Russian]

Yailenko, V.P. (2017). Istoriia i epigrafika Olvii, Khersonesa, Bospora VII v. do n.e. - VII v. n.e. [A History and Epigraphy of Olbia, Chersonesus and Bosporus VII Century B.C. - VII century A.D.]. SanktPeterburg [in Russian].

\section{Nikolai Nikolaev}

(Independent researcher, Mykolaiv, Ukraine)

ORCID: https://orcid.org/0000-0003-3994-1150

\section{Prosopographical Reconstruction of the Reduced and Fragmented Names of Historical Persons (on the Example of Olbia)}

When reconstructing fragmented names in epigraphy, the onomastic principle is traditionally used: the fragment is supplemented with suitable names, taking into account the approximate number of missing letters. For example, in the collection «Inscriptions in Olbia. 1968» (hereinafter - IOlb) the remains of letters [...] lov inscriptions IOlb 21 were restored by

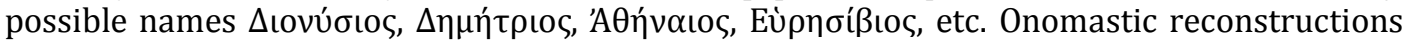
were widely used by V.V. Latyshev in his work "Latyshev B. Inscriptiones antique orae septentrionalis Ponti Euxini Graecae et Latinae. Petropolis. 1916» (hereinafter - IPE $\mathrm{I}^{2}$ ) and other researchers (for example, «Supplementum epigraphicum Graecum. Brill» (hereinafter SEG)); at the same time, the recovered names were used neither in Olbia nor in the Northern Black Sea region. Onomastic reconstruction of names, assuming the diversity of possible theoretical variants, remains essentially provisional, since it is not associated with a certain historical figure. Accordingly, the goal of the paper is to substantiate and protect a fundamentally different, prosopographical approach to the reconstruction of the fragmented (reduced) names of historical persons, as well as overcoming the opponent's criticisms.

The restoration of the chronology of Olbia of the $4^{\text {th }}-1^{\text {st }}$ centuries BC (synchronization of the eponym catalogue IPE I2 201) made by the author, opened the prospect of replacing traditional onomastic reconstruction with a fundamentally different, however, completely obvious approach to reconstruction of fragments and reduced names in monuments of a lapidary, ceramic, magical epigraphy and numismatics with the names of real historical persons - prosopographical reconstruction. As it is known, prosopography, because of its relatively "young age», is traditionally considered secondary to onomastics, linguistics, and paleography. The paradox is that when an appropriate level of study of a specific urban community, for example, Olbia, is reached, prosopography becomes dominant in the study of monuments containing the names of historical persons, including the ones in the form of fragments or reduced names. In the urban community of the ancient polis, a very limited number of persons was mentioned in lapidary or other inscriptions and coin legends. Those real historical persons came from the highest elite. The restoration of Olbia eponymous chronology was accompanied by obtaining representative prosopographical information about the members of seven elite families. That made it possible to substantiate the prosopographical approach to the reconstruction of the fragmented and reduced names of historical persons. Prosopography is successfully used in lapidary, ceramic, magical epigraphy and numismatics of Olbia (Tauric Chersonesos). In the monograph of V.P. Yailenko, 2017, the studies on the reconstruction of fragmented names were heavily criticized from traditional positions. The criticism of V.P. Yailenko is overcome and the goal of the paper is achieved by unequivocal confirmation of the fragment of dedication SEG 58:766 prosopographical reconstruction performed 10 years ago when it was combined with the previously known inscription IOlb 125.

Keywords: Olbia, epigraphy, reconstruction, onomastics, prosopography 